Saleh, Kutaiba; Unger, Volkmar; Dietzel, Alexander; Heydenreich, Detlef;

Großjohann, Rico; Jürgens, Clemens; Tost, Frank; Haueisen, Jens:

\title{
Evaluation of a novel method to measure the intraocular pressure based on a mechanical eye model
}

Zuerst erschienen in: Biomedical Engineering = Biomedizinische Technik. - Berlin [u.a.] : de Gruyter. - 57 (2012), Suppl. 1, Track-P, p. 834.

Erstveröffentlichung: $\quad$ 2012-09-06

ISSN (online): $\quad$ 1862-278X

ISSN (print): $\quad$ 0013-5585

DOI: $\quad 10.1515 / \mathrm{bmt}-2012-4355$

[Zuletzt gesehen: 2019-08-15]

„Im Rahmen der hochschulweiten Open-Access-Strategie für die Zweitveröffentlichung identifiziert durch die Universitätsbibliothek IImenau."

"Within the academic Open Access Strategy identified for deposition by Ilmenau University Library."

„Dieser Beitrag ist mit Zustimmung des Rechteinhabers aufgrund einer (DFGgeförderten) Allianz- bzw. Nationallizenz frei zugänglich."

"This publication is with permission of the rights owner freely accessible due to an Alliance licence and a national licence (funded by the DFG, German

Research Foundation) respectively." 


\title{
Evaluation of a novel method to measure the intraocular pressure based on a mechanical eye model
}

\author{
K. Saleh ${ }^{1}$, V. Unger ${ }^{1}$, A. Dietzel ${ }^{1}$, D. Heydenreich ${ }^{2}$, R. Großjohann ${ }^{3}$, C. Jürgens ${ }^{3}$, F. Tost ${ }^{3}$, J. Haueisen ${ }^{1}$ \\ kutaiba.saleh@tu-ilmenau.de \\ 1) Institute of Biomedical Engineering and Informatics, Ilmenau University of Technology, D- 98684, Ilmenau, \\ Germany \\ 2) Elektronik \& Präzisionsbau Saalfeld (EPSa) GmbH, D-07745 Jena, Germany \\ ${ }^{3)}$ Department of Ophthalmology, University Medicine Greifswald, D-17475 Greifswald, Germany
}

\section{Introduction}

A novel method using a sensor head consisting of one central and four peripheral pressure sensors placed in a radius of $1.6 \mathrm{~mm}$ is proposed for intraocular pressure (IOP) measurements. The aim of the present work is to evaluate the novel measuring method using a mechanical eye model (BiomechEye) with an exchangeable cornea and adjustable position of the sensor head against the cornea.

\section{Methods}

The different biomechanical properties of the human cornea were simulated using artificial corneas made from silicon with shore hardnesses of 0.6 and $1.0 \mathrm{MPa}$ and cornea thicknesses of 0.2 and $0.5 \mathrm{~mm}$. The different inner pressures in the BiomechEye (10 to 30 in steps of $5 \mathrm{mmHg}$ ) were emulated with a stepping motor with screw gearing and piston. Errors in sensor positioning are emulated ( 0.01 to $1.0 \mathrm{~mm}$ in steps of $10 \mu \mathrm{m})$ by moving the sensor head relative to the cornea via a linear table.

\section{Results}

Stiffness and internal pressure were determined by calculating the signal difference between the average peripheral and the central sensor signals. This difference signal showed a peak followed by a decline to a plateau. The value of the first inflection point is proportional to the IOP value. The difference between the peak and the followed plateau is proportional to the stiffness. Correction curves were identified according to the used corneas to calculate the correct IOP independent from the individual corneal properties. The mean IOP error was $1.8 \pm 1.3 \mathrm{mmHg}$. Errors resulting from faulty sensor head positioning were detected by the characteristics of the opposite peripheral sensor. The difference between the calculated and actual position was $\pm 0.2 \mathrm{~mm}$.

\section{Conclusion}

The measurement results show the possibility to calculate IOP taking into account the biomechanical properties of the cornea and to correct errors in sensor head positioning. 